\title{
Kinetics Study of Acid Catalyzed Degradation of Glucose in High-Temperature Liquid Water
}

\author{
Atiqa Rahmawatia, Aulia lin Saputrib ${ }^{\mathrm{b}}$ Ignatius Gunardi \\ aUniversitas Jember, ${ }^{a, b, c}$ Institut Teknologi Sepuluh Nopember, Indonesia \\ e-mail: tiga054@gmail.com
}

\begin{abstract}
Glucose is the most abundant monosaccharide in nature, glucose obtained from cellulose and starch, it is many used to degradation process, and for the production of several organic compounds, one of the degradation products of glucose is an HMF (5-hydroxymethylfurfural). HMF is a platform chemical, which can be converted into several chemical and liquid fuels through hydrogenation, oxidation, and esterification. The objective of this researches has studied the kinetics of glucose degradation using acid-catalyzed (H2SO4) in high-temperature liquid water and observe the effect of acid concentration and temperature on degradation of glucose to HMF. In this research was used reactor with pressure $10 \mathrm{~atm}$, with variation time of reaction, sulfuric acid concentration, and temperature of the reaction. From this research found kinetics of glucose degradation was followed by the first-order reaction in each variable. Activation Energy (Ea) values were 7306,593 J/mol; $6341,59 \mathrm{~J} / \mathrm{mol}$; $3988,14 \mathrm{~J} / \mathrm{mol}$ and $3988,14 \mathrm{~J} / \mathrm{mol}$ on the concentration sulfuric acid $0,05 \mathrm{M}$; $0,1 \mathrm{M} ; 0,05 \mathrm{M}$, from that result indicated that reaction rate was increase when activation energy was decrease this was related to Arrhenius equation. The effect of acid concentration on degradation glucose was the higher acid concentration used, the more glucose was degraded, and more HMF was formed. Meanwhile, the effect of temperature of reaction on degradation glucose was the higher temperature of the reaction, more glucose was degraded, and more HMF was formed. The highest value of HMF was in operation condition of concentration $\mathrm{H} 2 \mathrm{SO} 40,5 \mathrm{M}$ at $175^{\circ} \mathrm{C}$, with a time of reaction 120 minutes. However, the reduction rate of glucose was not equal to the rate of formation of HMF (5-hydroxymethylfurfural), it can be indicated that HMF (5-hydroxymethylfurfural) was not the only product of degradation of glucose, but the others product might be formed from this operating condition. The other product that might be formed was humin and levulinic acid.
\end{abstract}

Keywords: degradation of glucose, kinetics study, hydroxymethyl furfural (HMF)

\section{INTRODUCTION}

The decreasing of fossil fuel has become a global concern; combustion of fossil fuel have a severe impact in environments such as climate change and pollutant emission [1]. To cut-off, these problems renewable energy become one of the sustainable solution [1]. Biomass is one of the renewable resources to replace fossil fuel for the production of organic chemicals. Some technology can provide a route to convert biomass into fuel or chemicals [2]. Lignocellulosic biomass is a biopolymer which consists of cellulose (40$60 \%)$, hemicellulose $(20-40 \%)$, and lignin $(10-24 \%)$. Degradation of the cellulose and hemicellulose result in formation hexose and pentose sugar, which could be used to producing variety value-added product such as 5-Hydroxymethylfurfural and furfural [1]. HMF is a platform chemical that receives noteworthy attention as a key bio-refining building block. Some methods used to produce HMF from biomass are hydrolysis, isomerization, degradation methods with acidic or basic catalysts. [3]. Besides, HMF can 
be converted to promising biofuel (2,5-dimethylfuran) which produced from petroleum [3]. Attention to HMF is increasing due to the application of HMF as a substitute material for petroleum-based building blocks. Fructose is a monosaccharide which easies to convert over a homogenous and heterogeneous acidic catalyst in the aqueous or organic phase, ionic liquids, and multiphase system [4]. The high price of fructose and the low availability of fructose has led to increasing in glucose as raw materials to produce HMF using the dehydration method [4].

Production of HMF from sugar via dehydration reaction and using variety acidic ionic liquids as a solvent could hydrolyze cellulose to sugar and HMF. However, organic solvents that have a high boiling point will be difficult to remove, moreover in this process also result in adverse impacts on the environment. [1]. Water is a unique and environmentally friendly solvent, besides being able to act as a solvent and reactant, water can be catalyzed in pressurized water. As a green solvent that has unique properties, water is used as an alternative solvent in biomass conversion. [1]. Besides, using solvents such as ionic liquids that have high boiling points will result in high-cost in the process because of the difficult separation and purification process, thus to avoid this problem it would be preferable to use water as a solvent in the dehydration process [4]. In the dehydration process, acid catalyst use as attractive processing option to produce HMF from hexoses and pentoses [5]. Study of glucose degradation in Hot Compressed Water $(\mathrm{HCW})$ with catalysts or without catalysts have been shown that $\mathrm{H}_{2} \mathrm{SO}_{4}$ and $\mathrm{NaOH}$ catalysts affect the process of glucose degradation reaction into products [1].

Pornlada et al. studied the dehydration of cellulose in hot compressed water by using acidic and base catalysts to produce HMF. The operating conditions used was 200 $-230^{\circ} \mathrm{C}$ for 5 minutes. The optimum yield of HMF was $7.5 \%$ [1]. The other study using acid catalyst in dehydration sugar mentioned that the highest product yield was obtained at $150{ }^{\circ} \mathrm{C}$ and $0,55 \mathrm{M} \mathrm{H}_{2} \mathrm{SO}_{4}$ [2]. Cunshan Zhou et al. [3] had studied the conversion of glucose to HMF in different solvent and catalyst, from that studied was obtained HMF yield in the various solvents follows a decreasing order as DMSO $>[\mathrm{Bmim}] \mathrm{Cl}>\mathrm{H} 2 \mathrm{O}$. In the study of glucose degradation carried out in DMSO solvents using several catalysts. It was obtained yield HMF from low to high by using a catalyst $\mathrm{FeCl}_{3} .6 \mathrm{H}_{2} \mathrm{O}, \mathrm{AlCl}_{3}, \mathrm{CrCl}_{3} .6 \mathrm{H}_{2} \mathrm{O}$. The optimal yield of $\mathrm{HMF}$ was obtained $54.4 \%$ using the $\mathrm{CrCl}_{3} .6 \mathrm{H}_{2} \mathrm{O}$ catalyst at $403 \mathrm{~K}$ for 480 minutes and $52.86 \%$ using the $\mathrm{AlCl}_{3}$ catalyst at $393 \mathrm{~K}$ for 240 minutes [3].

Based on previous studies, HMF can be produced from sustainable material such as lignocellulose. However, to convert lignocellulose to HMF requires a very long process, starting from sample preparation, lignin removal, hydrolysis process to produce glucose. Glucose from the hydrolysis process will be converted to HMF using dehydration process. In this study, we have examined an acid catalyst and water solvent to produce HMF. The process to form HMF is the dehydration using acid catalysts and water solvents, and the process will be carried out at high temperature pressured reactors.

\section{MATERIALS AND MethodS}

D-Glucose $(\geq 99,5 \%)$, sulfuric acid $(98 \%)$ were purchased from Sigma-Aldrich. 3,5dinitrosalicylic acid (DNS), natrum hydroxide, potassium sodium tartrate, sodium metabisulphite for glucose analysis were also acquired from Sigma-Aldrich. Glucose Solution was prepared using aquadest.

\section{Glucose Degradation}

All experiment was carried out in a batch reactor type stirred tank with stainless steel material (volume $600 \mathrm{ml}$, height $25 \mathrm{~cm}$, OD $7,5 \mathrm{~cm}$ ) equipped with a four-blade turbine stirrer. A solution of glucose $1 \%$ with catalyst concentration $0,5 \mathrm{M} ; 0,1 \mathrm{M} ; 0,05 \mathrm{M}$ were fed to the reactor system. The reactor was flow by $\mathrm{N}_{2}$ gas to expel the air inside the reactor. The reactor was heated at $100,125,150,175{ }^{\circ} \mathrm{C}$, pressure in the system was $10 \mathrm{~atm}$. The sample was taken at 0, 30, 60, 90, and 120 minutes. Reduced glucose was analyzed using visible spectrophotometer detector (Cecil CE 1011) with a wavelength of $540 \mathrm{~nm}$, then HMF product was analyzed by HPLC Agilent 1100 series with refractive index detector in ULFPP Airlangga University Surabaya. 


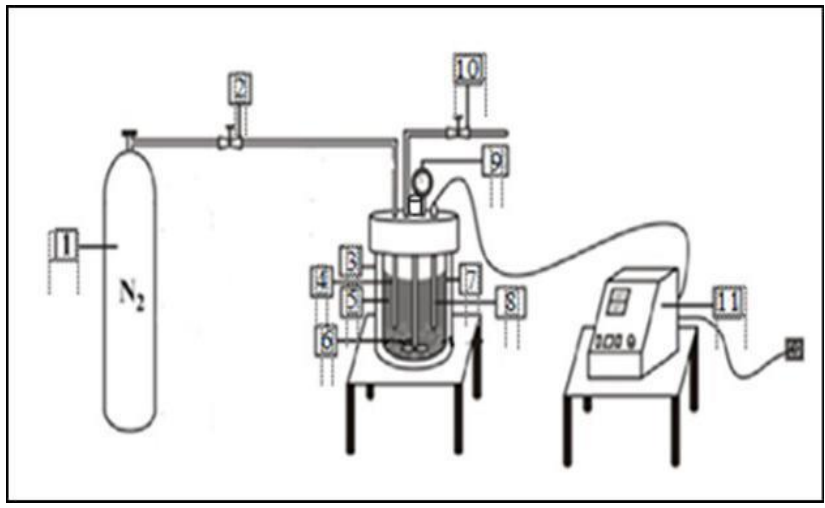

1. $\mathrm{N}_{2}$ gas

2. Valve tube gas $\mathrm{N}_{2}$

3. Heater

4. Reactor Tube $\mathrm{N}_{2}$ gas

5. Glucose and catalyst solution

6. Stirrer

7. Reactor

8. Thermocouple tube

9. Pressure indicator

10. Gas outlet valve and sampling valve

11. Panel control heater- reactor

Figure 1. Reactor equipment for glucose degradation

\section{Analysis}

The products present in the reaction were analyzed by HPLC Agilent 1100 series with refractive index detector in ULFPP Airlangga University Surabaya. Reduce glucose from the products were analyzed by visible spectrophotometer detector (Cecil CE 1011) with a wavelength of $540 \mathrm{~nm}$ with DNS reagent.

\section{Kinetic Modelling}

To determine the reaction rate $(k)$ and the order of reaction $(n)$ in the formation of HMF (Hydroxymethylfurfural), it is known from the equation, the relationship between $t$ (time) and -In CA / CAO. The equation for the reaction is as follows:

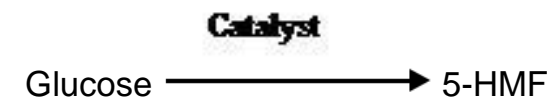

The integral method was used in this kinetic model, with assumption first-orderer reaction to glucose. The assumption was correct if the equation forms a straight line, and the reaction order of the HMF formation from glucose occurs in the first-orderer reaction.

$$
\begin{aligned}
& -r_{A}=-\frac{d_{A}}{d t}=k\left[C_{A}\right]^{n} \\
& -r_{A}=-\frac{d C_{A}}{d t}=k\left[C_{A}\right]^{1}
\end{aligned}
$$

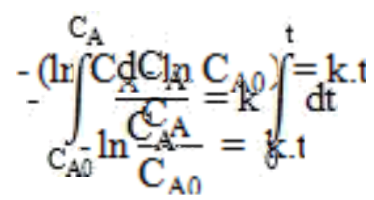

\section{Results AND Discussions \\ Glucose Degradation}

From this study, we use an initial concentration of glucose was $1 \%$, then adding several acid catalyst concentration. Product form depends on the initial glucose concentration [6]. Fig 2 shows the effect time of reaction toward reduction of glucose concentration in acid concentration. Increasing temperature and reaction time, the concentration of glucose decreased. Since glucose concentration inversely proportional 
to temperature and reaction time, increasing in temperature and reaction time would result in reducing glucose concentration [7].

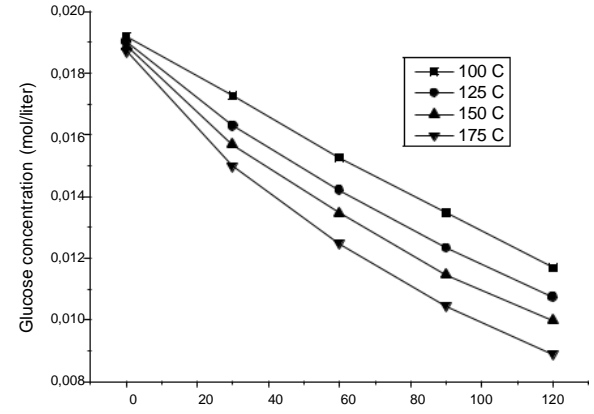

time of reaction (minutes)

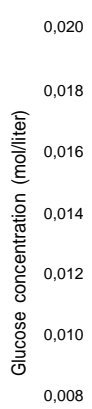

$$
\begin{aligned}
& 100 C \\
& 125 C \\
& 150 C \\
& 175 C
\end{aligned}
$$

0,018
0,016
0,014
0,012
0,010

0,008 time of reaction (minutes)

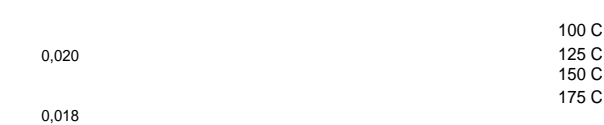

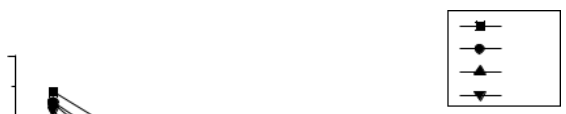
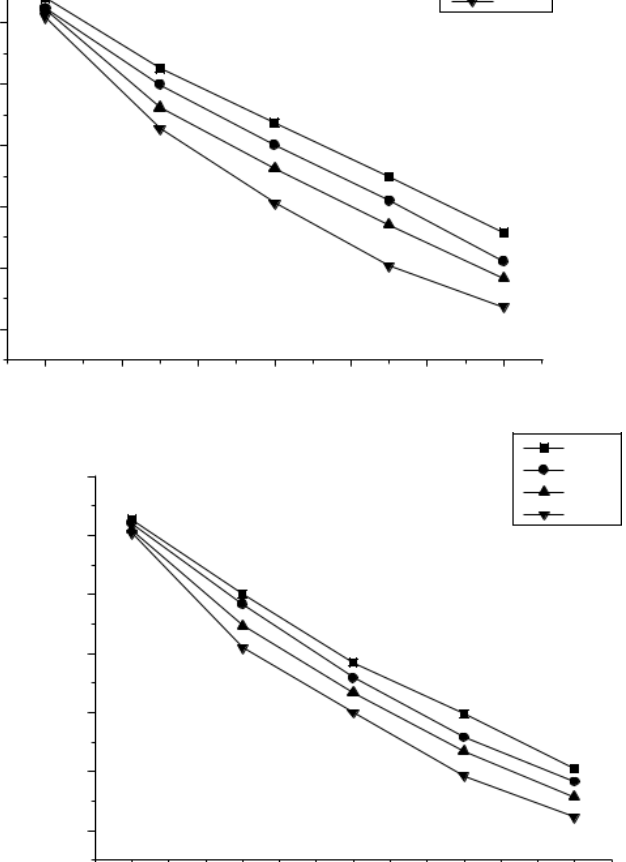

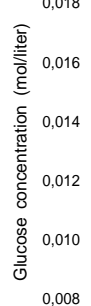

time of reaction (minutes)

Figure 2. Effect temperature and reaction time to glucose concentration at (a) $0,05 \mathrm{M} \mathrm{H}_{2} \mathrm{SO}_{4}$,

(b) $0,1 \mathrm{M} \mathrm{H}_{2} \mathrm{SO}_{4}$, (c) $0,5 \mathrm{M} \mathrm{H}_{2} \mathrm{SO}_{4}$

\section{HMF (Hydroxymethylfurfural) Formation}

HMF (Hydroxymethylfurfural) or 5-HMF is high importance platform chemical derived from biomass. In this study, the conversion of glucose to 5-HMF was performed in a batch reactor of various concentration acid catalyst then analyzed by using HPLC Agilent 1100 series with a refractive index detector. Fig 3 shows effect reaction time and temperature to $\mathrm{HMF}$ formation in $\mathrm{H} 2 \mathrm{SO} 4$ concentration. From that figures show Increasing reaction time and temperature obtained a high concentration of HMF. This is in accordance with the other study mentioned that HMF concentration would be higher when the temperature increase [7]. From fig 3 at $150-175^{\circ} \mathrm{C}$ at reaction time $0-30$ 
minutes HMF concentration had increased significantly, this is because HMF concentration had increased at $160^{\circ} \mathrm{C}$ with reaction time 30 minutes [8]. The other study mentioned that the formation of $\mathrm{HMF}$ occurred in $150-200^{\circ} \mathrm{C}$ using acid catalyst $\mathrm{H} 2 \mathrm{SO} 4$ [2]. At reaction time $60-120$ minutes HMF concentration tended to constant since HMF had redehydration reaction, which forms levulinic acid and formic acid [8]. The other study mentioned that the chemical conversion of glucose could proceed via acid-catalyzed dehydration and obtained 5-HMF, levulinic acid, and formic acid at $150{ }^{\circ} \mathrm{C}$ [9]. The highest conversion of glucose to HMF was $18,495 \%$, meanwhile the other study mentioned that conversion of glucose to HMF was $91,4 \%$, and yield of HMF was $59,8 \%$ using Indium trichloride ( $\mathrm{InCl} 2$ ) as catalyst in aqueous solution [10], Study of Quhe Ren et al. mentioned that conversion of glucose was $86 \%$ and yield of $\mathrm{HMF}$ was $63 \%$, this study using metal halide ( $\mathrm{Nal}$ dan $\mathrm{NaBr}$ ) as catalyst [11]. Result of Yanhua wang study was the highest yield HMF $76 \%$ using fructose as raw material, heterogeneous catalyst, and solvent DMSO [12]. From that statement to increasing glucose conversion and yield of $\mathrm{HMF}$, we can use heterogeneous catalysts such as InCl2, $\mathrm{Nal}, \mathrm{NaBr}$, and an ionic liquid solvent.
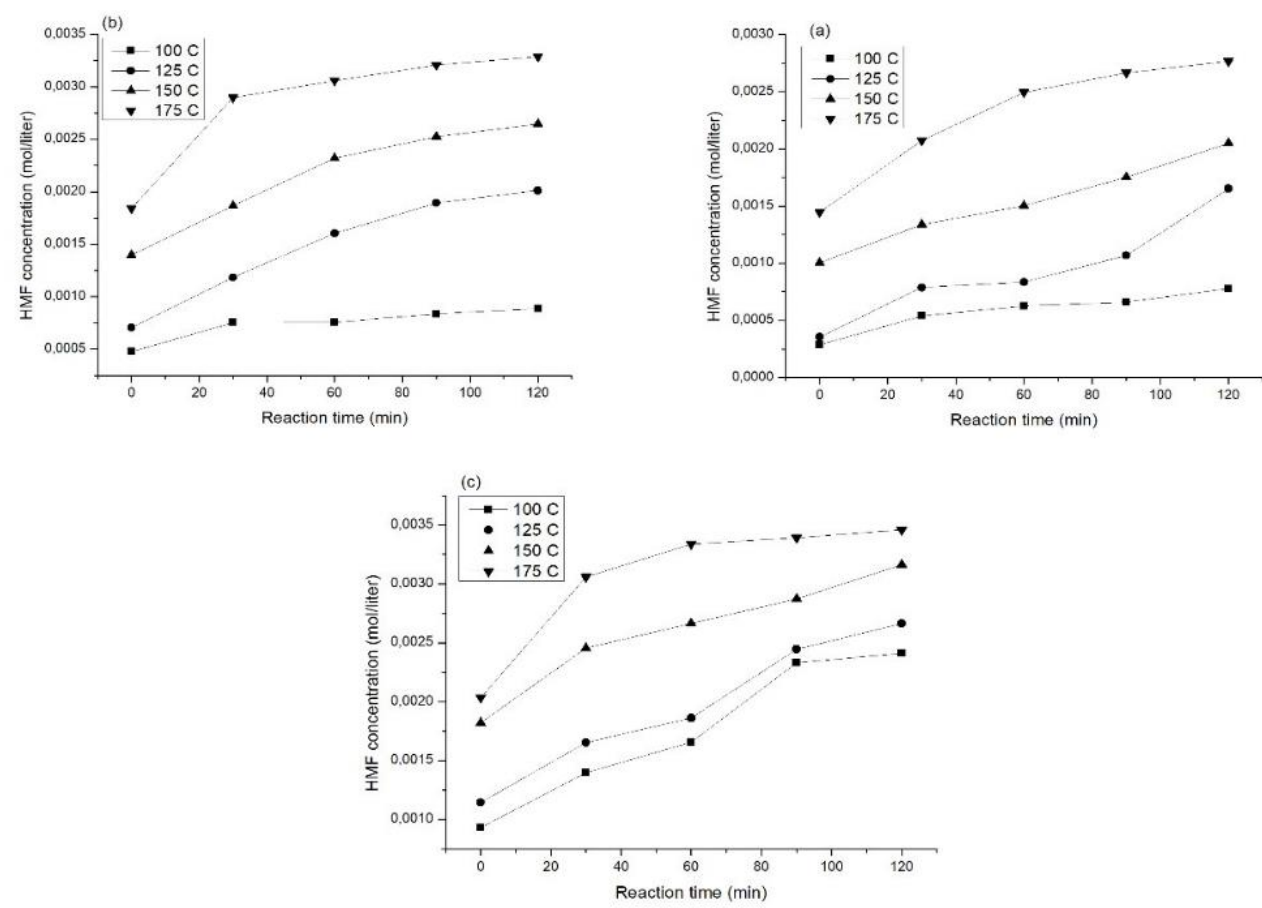

Figure 3. Effect reaction time and temperature to $\mathrm{HMF}$ formation (a) $0,05 \mathrm{M} \mathrm{H}_{2} \mathrm{SO}_{4}$, (b) 0,1 $\mathrm{M}$ $\mathrm{H}_{2} \mathrm{SO}_{4}$, (c) $0,5 \mathrm{M} \mathrm{H}_{2} \mathrm{SO}_{4}$

\section{Kinetic Modelling}

Glucose degradation experiment initially used acids concentration 0,$05 ; 0,1 ; 0,5 \mathrm{M}$, and temperature at four level $100,125,150,175^{\circ} \mathrm{C}$. Temperature and acid concentration were independent variables in this study. Equation 1 shows the reaction scheme for development kinetic model for acid-catalyst degradation of glucose based on the following consideration and assumption:

Assume all reaction rate equation using first - order reaction.

1. The desired product from glucose degradation using an acid catalyst is the formation of HMF. However, in this degradation process obtained by-products (levulinic acid and humin) simultaneously, which are undesirable and neglected in the process.

2. Kinetic modeling using an integral method first-order reaction. 
In batch reactor set up with constant density and volume, ay change in the concentration of the individual species as a function of time, maybe represented by the following equation:

$$
-\mathrm{r}_{\mathrm{A}}=-\frac{\mathrm{dC}_{\mathrm{A}}}{\mathrm{dt}}=\mathrm{k}\left[\mathrm{C}_{\mathrm{A}}\right]^{\mathrm{n}}
$$

For this section, separating and integrating we obtain

$$
\begin{aligned}
-\int_{\mathrm{C}_{\mathrm{A} 0}}^{\mathrm{C}_{\mathrm{A}}} \frac{\mathrm{dC}_{\mathrm{A}}}{\mathrm{C}_{\mathrm{A}}} & =\mathrm{k} \int_{0}^{\mathrm{t}} \mathrm{dt} \\
-\ln \frac{\mathrm{C}_{\mathrm{A}}}{\mathrm{C}_{\mathrm{A} 0}} & =\mathrm{k} \cdot \mathrm{t}
\end{aligned}
$$

A plot of In (CA/CA0) vs. $t$ gives a straight line through the origin for this form of rate equation. If the straight line was obtained, the assumption was right that kinetic of glucose degradation occurs in first-order reaction. Fig 4 shows reaction time to $\ln (\mathrm{CA} / \mathrm{CA} 0)$ at various acid-catalyst concentration.
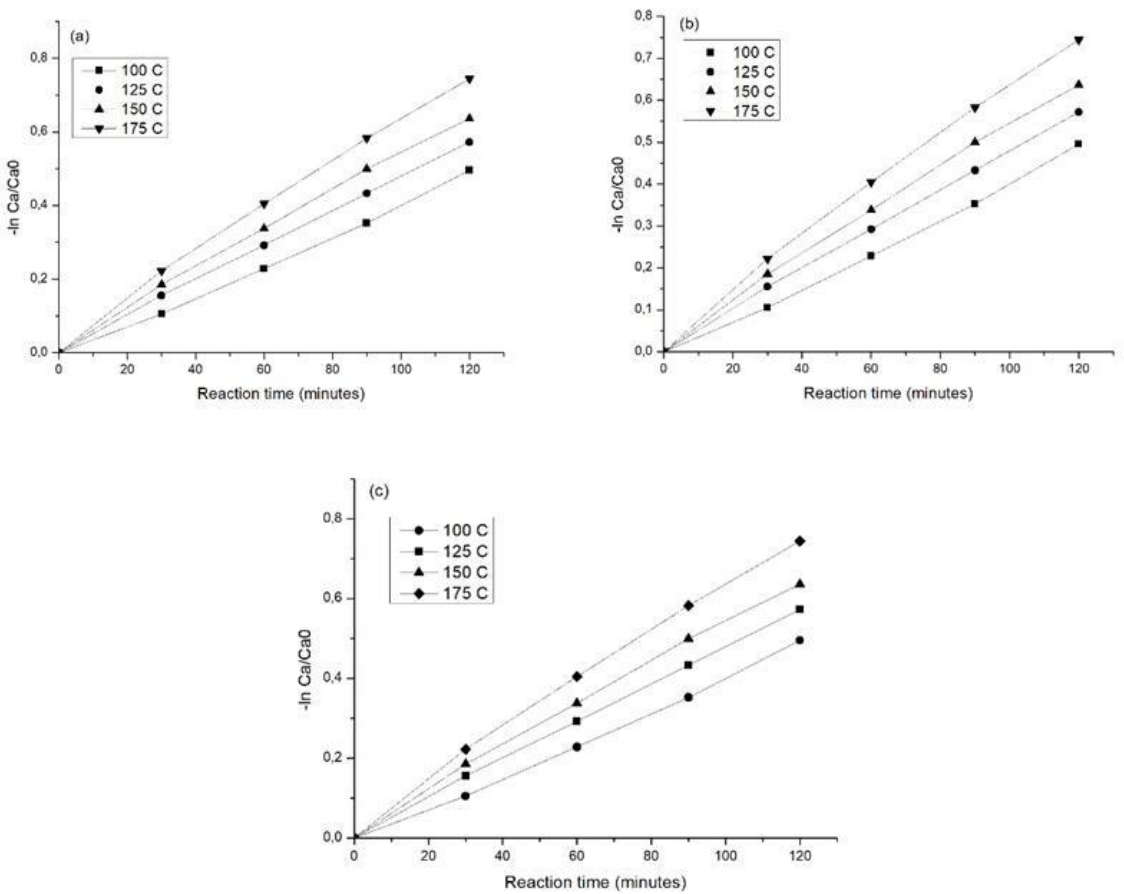

Figure 4. A plot of In (CA/CAO) to temperature at (a) 0,05 M H2SO4, (b) 0,1 M H2SO4, (c) 0,5 M
H2SO4

Fig 4 shows all the experimental data have a straight line which indicates the reaction occur in first-order reaction. Others study mention that degradation glucose occurs in the first-order reaction [7], [6]. 
Table 1. Effect of temperature to reaction rate constant

\begin{tabular}{|c|c|c|c|}
\hline $\begin{array}{c}\mathrm{H}_{2} \mathrm{SO}_{4} \\
\text { Concentration }\end{array}$ & $\begin{array}{c}\text { Temperature } \\
\left({ }^{\circ} \mathrm{C}\right)\end{array}$ & k & n \\
\hline & 100 & 0,00503 & 1 \\
\hline & 125 & 0,00543 & 1 \\
\hline \multicolumn{4}{|l|}{$0.5 \mathrm{M}$} \\
\hline & 150 & 0,00569 & 1 \\
\hline & 175 & 0,00630 & 1 \\
\hline & 100 & 0,00428 & 1 \\
\hline & 125 & 0,00485 & 1 \\
\hline \multicolumn{4}{|l|}{$0.1 \mathrm{M}$} \\
\hline & 150 & 0,00527 & 1 \\
\hline & 175 & 0,00610 & 1 \\
\hline & 100 & 0,00413 & 1 \\
\hline & 125 & 0,00474 & 1 \\
\hline \multicolumn{4}{|l|}{$0.05 \mathrm{M}$} \\
\hline & 150 & 0,00525 & 1 \\
\hline & 175 & 0,00620 & 1 \\
\hline
\end{tabular}

From table 1, we can conclude that the reaction rate constant is directly proportional to the temperature. When the temperature rises, the reaction rate constant also rises. In the concentration acid-catalyst 0,$5 ; 0,1 ; 0,05 \mathrm{M}$ the reaction rate constant have been increased with the temperature. This is in accordance with the Arrhenius equation.

$k=k_{0} e^{-E / R T}$

$\mathrm{k}=$ reaction rate constant $\left(\mathrm{mol} / \mathrm{m}^{3}\right)^{1-\mathrm{n}} \mathrm{s}^{-1}, \mathrm{k} 0=$ pre-exponential factor $\left(\mathrm{mol} / \mathrm{m}^{3}\right) \mathrm{s}^{-1} 1, \mathrm{Ea}=$ Activation energy of reaction $(\mathrm{J} / \mathrm{mol})^{\prime} \mathrm{R}=$ ideal gas constant. From that equation, we could see the greater the temperature in a reaction, the constant rate of formation of HMF (Hydroxymethylfurfural) increases, the rate of HMF formation (Hydroxymethylfurfural) also increases. Since the temperature of a reaction raises, the reacting particles will move faster so that the frequency of collisions is greater.

Table 2. Activation energy

\begin{tabular}{cc}
\hline $\begin{array}{c}\text { Acid catalyst } \\
\text { concentration }\end{array}$ & Ea $(\mathrm{J} / \mathrm{mol})$ \\
\hline $0,5 \mathrm{M}$ & 3988,14 \\
$0,1 \mathrm{M}$ & 6341,59 \\
$0,05 \mathrm{M}$ & 7306,59 \\
\hline
\end{tabular}

From table 2, we can conclude that the higher catalyst concentration, activation energy will be decreased. This is in accordance with Levenspiel, who states that the reaction rate and activation energy are inversely proportional so that the higher the catalyst concentration, the rate of reaction increases and the activation energy decreases. The activation energy has a dependency on temperature, reaction with high activation energies are very temperature-sensitive. Reaction with low activation energies are relatively temperature-sensitive. 


\section{Conclusion}

The value of the rate of glucose degradation is not the same as the rate of formation of HMF, it can be indicated that HMF is not the only result of glucose degradation, but there are other compounds formed in the process of glucose degradation. The greatest concentration of HMF (Hydroxymethylfurfural) at operation condition $0,5 \mathrm{M}$ acid-catalyst concentration, the temperature of $175^{\circ} \mathrm{C}$, reaction time $=120$ minutes was $0.003458 \mathrm{~mol}$ / L. In this study kinetic degradation of glucose into HMF follow first-order reaction, and the reaction rate constant proportional to rate formation of HMF. Activation Energy (Ea) values were $7306,593 \mathrm{~J} / \mathrm{mol} ; 6341,59 \mathrm{~J} / \mathrm{mol} ; 3988,14 \mathrm{~J} / \mathrm{mol}$ and $3988,14 \mathrm{~J} / \mathrm{mol}$ on the concentration sulfuric acid $0,05 \mathrm{M} ; 0,1 \mathrm{M} ; 0,05 \mathrm{M}$, from that result indicated that reaction rate was increase when activation energy was decrease this was related to Arrhenius equation. The effect of acid concentration on degradation glucose was the higher acid concentration used, the more glucose was degraded, and more HMF was formed. Meanwhile, the effect of temperature of reaction on degradation glucose was the higher temperature of the reaction, more glucose was degraded, and more HMF was formed.

\section{ACKNOWLEDGMENTS}

Chemical Reaction Engineering Laboratory, Chemical Engineering Faculty, Institut Teknologi Sepuluh Nopember Surabaya.

\section{REFERENCES}

1. P. Daorattanachai, S. Namuangruk, N. Viriya-empikul, and N. Laosiripojana, "Journal of Industrial and Engineering Chemistry 5-Hydroxymethylfurfural production from sugars and cellulose in acid- and base-catalyzed conditions under hot compressed water," J. Ind. Eng. Chem., vol. 18, no. 6, pp. 1893-1901, 2012.

2. B. Girisuta, K. Dussan, D. Haverty, J. J. Leahy, and M. H. B. Hayes, "A kinetic study of acid catalysed hydrolysis of sugar cane bagasse to levulinic acid," Chem. Eng. J., vol. 217, pp. 61-70, 2013.

3. C. Zhou, J. Zhao, A. Elgasim, A. Yagoub, and H. Ma, "Conversion of glucose into 5hydroxymethylfurfural in different solvents and catalysts: Reaction kinetics and mechanism," Egypt. J. Pet., vol. 26, no. 2, pp. 477-487, 2017.

4. V. V Ordomsky, V. L. Sushkevich, J. C. Schouten, J. Van Der Schaaf, and T. A. Nijhuis, "Glucose dehydration to 5-hydroxymethylfurfural over phosphate catalysts," J. Catal., vol. 300, pp. 37-46, 2013.

5. A. Toftgaard, R. Ringborg, T. Grotkjær, S. Pedersen, and J. M. Woodley, "Synthesis of 5-hydroxymethylfurfural ( HMF ) by acid catalyzed dehydration of glucose fructose mixtures," vol. 273, pp. 455-464, 2015.

6. L. Kupiainen, J. Ahola, and J. Tanskanen, "Chemical Engineering Research and Design Kinetics of glucose decomposition in formic acid," Chem. Eng. Res. Des., vol. 89, no. 12, pp. 2706-2713, 2011.

7. S. W. Mckibbins, J. F. Harris, J. F. Saeman, and W. K. Neill, "Kinetics of the Acid Catalyzed Conversion of Glucose to 5-Hydroxymethyl-2-Furadehyde and Levulinic Acid 1."

8. N. S. Mosier, C. M. Ladisch, and M. R. Ladisch, "Characterization of Acid Catalytic Domains for Cellulose Hydrolysis and Glucose Degradation," 2002.

9. A. Herbst and C. Janiak, "levulinic acid with MIL-101Cr MOF-derivatives $\dagger$," pp. 7958-7967, 2016.

10. Y. Shen, J. Sun, Y. Yi, B. Wang, F. Xu, and R. Sun, "Journal of Molecular Catalysis A: Chemical 5-Hydroxymethylfurfural and levulinic acid derived from monosaccharides dehydration promoted by $\mathrm{InCl} 3$ in aqueous medium," "Journal Mol. Catal. A, Chem., vol. 394, pp. 114-120, 2014.

11. Q. Ren, Y. Huang, H. Ma, J. Gao, and J. Xu, "Catalytic conversion of carbohydrates to 5 - hydroxymethylfurfural promoted by metal halides," Chinese J. Catal., vol. 35, no. 4, pp. 496-500, 2014.

12. Y. Wang, $\mathrm{X}$. Tong, $\mathrm{Y}$. Yan, S. Xue, and $\mathrm{Y}$. Zhang, "Ef fi cient and selective conversion of hexose to 5-hydroxymethylfurfural with tin - zirconium-containing heterogeneous catalysts," CATCOM, vol. 50, pp. 38-43, 2014. 